\title{
PEREIVED
}

LA-UR-y 3

\section{JUL 311998}

Approved for public release distribution is unlimited.

Title:

THE ACTION CHARST T LINK BETWEEN HERA (HUMAN EVENTS

REFERENCE FOR ATHEANA) AND ATHEANA (A TECHNIQUE FOR HUMAN ERROR ANALYSIS)
Author(s):

Submitted to:

Heidi A. Hahn

\section{United States Nuclear Regulatory}

Commission

\section{Los Alamos \\ NATIONAL LABORATORY}

Los Alamos National Laboratory, an affirmative action/equal opportunity employer, is operated by the University of California for the U.S. Department of Energy under contract W-7405-ENG-36. By acceptance of this article, the publisher recognizes that the U.S. Government retains a nonexclusive, royalty-free license to publish or reproduce the published form of this contribution, or to allow others to do so, for U.S. Government purposes. Los Alamos National Laboratory requests that the publisher identify this article as work performed under the auspices of the U.S. Department of Energy. The Los Alamos National Laboratory strongly supports academic freedom and a researcher's right to publish; as an institution, however, the Laboratory does not endorse the viewpoint of a publication or guarantee its technical correctness. 


\section{DISCLAIMER}

This report was prepared as an account of work sponsored by an agency of the United States Government. Neither the United States Government nor any agency thereof, nor any of their employees, makes any warranty, express or implied, or assumes any legal liability or responsibility for the accuracy, completeness, or usefulness of any information, apparatus, product, or process disclosed, or represents that its use would not infringe privately owned rights. Reference herein to any specific commercial product, process, or service by trade name, trademark, manufacturer, or otherwise does not necessarily constitute or imply its endorsement, recommendation, or favoring by the United States Government or any agency thereof. The views and opinions of authors expressed herein do not necessarily state or reflect those of the United States Government or any agency thereof. 


\section{DISCLAIMER}

Portions of this document may be illegible electronic image products. Images are produced from the best available original document. 
The Action Characterization Matrix: A Link between HERA (Human Events Reference for ATHEANA) and ATHEANA (A Technique for Human Error Analysis)

Prepared by: Heidl Ann Hahn, Ph. D. Los Alamos National Laboratory (LANL)

Prepared for: United States Nuclear Regulatory Commission (NRC)

Revised: December 22, 1997 


\section{Contents}

Page

1 Introduction $1-1$

1.1 Background $1-1$

1.2 Rationale for the Action Characterization Matrix 1-2

2 The Action Characterization Matrix 2-1

2.1 Development 2-1

2.2 Matrix Structure 2-2

2.3 Explanation of Matrix Dimensions 2-4

3 References $3-1$

Figures

2-1. High-level view of the Action Characterization Matrix.

Appendices

A: Glossary 


\section{Abbreviations}

$\begin{array}{ll}\text { ACM } & \text { Action Characterization Matrix } \\ \text { ATHEANA } & \text { A Technique for Human Error Analysis } \\ \text { EFC } & \text { error-forcing context } \\ \text { EOC } & \text { error of commission } \\ \text { EOO } & \text { error of omission } \\ \text { FOR } & \text { frame-of-reference } \\ \text { HPIP } & \text { Human Performance Investigation Process } \\ \text { IG } & \text { Implementation Guidelines } \\ \text { LANL } & \text { Los Alamos National Laboratory } \\ \text { NPP } & \text { nuclear power plant } \\ \text { NRC } & \text { Nuclear Regulatory Commission } \\ \text { PSF } & \text { performance shaping factor } \\ \text { HERA } & \text { Human Events Reference for ATHEANA } \\ \text { HRA } & \text { human reliability analysis } \\ \text { HSECS } & \text { Human-System Event Classification Scheme } \\ \text { PRA } & \text { probabilistic risk assessment } \\ \text { UA } & \text { unsafe action }\end{array}$




\section{Introduction}

\subsection{Background}

The Technique for Human Error Analysis (ATHEANA) is a newly developed human reliability analysis (HRA) methodology that aims to facilitate better representation and integration of human performance into probabilistic risk assessment (PRA) modeling and quantification by analyzing risk-significant operating experience in the context of existing behavioral science models. The fundamental premise of ATHEANA is that error-forcing contexts 1 (EFCs), which refer to combinations of equipment/material conditions and performance shaping factors (PSFs), "set up" or create the conditions under which unsafe actions (UAs) can occur. (See the ATHEANA Frame-of-Reference [FOR] Manual [Taylor et. al., 1997] and Implementation Guidelines [IG; Bley et. al., 1997] for further information.) ATHEANA is being developed in the context of nuclear power plant (NPP) PRAs, and much of the language used to describe the method and provide examples of its application are specific to that industry. However, it is hoped that the method will be equally applicable in other high-risk/high-consequence areas, such as transportation, chemical processing, medicine, etc.

Because ATHEANA relies heavily on the analysis of operational events that have already occurred as a mechanism for generating creative thinking about possible EFCs, a database, called the Human Events Reference for ATHEANA (HERA), has been developed to support the methodology. (See Cooper, Luckas, and Wreathall, 1995, for a description of the database, which was then called the Human-System Event Classification Scheme or HSECS.) HERA, however, currently suffers from several weaknesses. First, initial database development efforts preceded completion of the development of the ATHEANA methodology. As a result, the conceptual links between the existing database and the ATHEANA framework are not as obvious as is desired. Second, although it was intended that the database be the repository for a set of examples that would aid ATHEANA analysts, entry of events into the database did not keep pace with

1 Italics indicate that a definition for the highlighted term is available in the glossary. Italics appear only upon first use of the term. 
generation of other ATHEANA-related documents. Thus, there are many events used as examples in these documents that are not available in the database. Finally, although ATHEANA documents use events from other industries (especially transportation) as examples, the database is currently not structured to accept non-NPP events in a meaningful way, nor is there a way to "equate" events from different industries such that learnings about EFCs in one industry could be generalized to stimulate thoughts about similar EFCs in another.

Los Alamos National Laboratory's (LANL) Human Factors Group has recently joined the ATHEANA project team; LANL is responsible for further developing the database structure and for analyzing additional exemplar operational events for entry into the database. Resolving the issues with HERA cited above is of highest priority.

\subsection{Rationale for the Action Characterization Matrix}

The Action Characterization Matrix ( $A C M$ ) is conceived as a bridge between the HERA database structure and ATHEANA. Specifically, the ACM allows each unsafe action or human failure event2 to be characterized according to its representation along each of six different dimensions: system status 3 , initiator status, unsafe action mechanism, information processing stage, equipment/material conditions, and performance shaping factors. (These dimensions are described in detail in Section 2.3.) While these dimensions have direct correlates in the ATHEANA methodology as well as direct representation in the database structure, in both cases, the information required (in the case of ATHEANA) or provided (in the case of HERA) is too detailed to provide a snapshot of the UA that allows it to be quickly placed in context (such as an error-forcing context

2 The ACM allows characterization of both unsafe actions and human failure events. Throughout the document, when the term UA is used, it is intended to refer to both.

3 Note that the word "system" is used to refer to an interacting group of components that contribute to a unified whole. In the NPP arena, "system" is meant to imply the plant. 
or a combination of unsafe action mechanism and information processing stage) and too NPP-specific to allow for cross-industry generalization.

The intention of the ACM is to provide a taxonomic description of an unsafe action in a short-hand form that:

- uses generic language, so that UAs having a particular constellation of characteristics can be understood as fitting into a similar context regardless of the industry from which they were derived,

- uses simple language, that makes the links between the complex ideas expressed in ATHEANA and the (of necessity) equally complex entries contained in the database more explicit, and

- is comprehensive enough to allow for a rapid understanding of the coverage of the possible exemplar space provided by a set of analyzed events.

For these reasons, development of the ACM was viewed as the necessary first step in resolving the problems with the HERA database described above. 


\section{The Action Characterization Matrix}

This section describes the development of the ACM and provides details on the structure and content of its dimensions.

\subsection{Development}

Because the ACM is intended to link ATHEANA and HERA, it was logical to derive its dimensions from source documents describing both the methodology and the database. The general approach to the derivation of the ACM was as follows:

- each of the existing ATHEANA and HERA documents (i.e., the FOR manual, the IG, and the HERA database descriptions, as well as less formal documents such as the viewgraphs used at the ATHEANA training session held for the NRC in May 1997 and new events analyses documents) was read and notes were kept regarding any categorical information provided (such asunsafe action mechanisms or performance shaping factors) as well as constituents of the categories,

- content analysis was used to cluster category constituents, eliminate duplications, and clarify the meaning of categories and their elements,

- determinations were made regarding the number of levels of subcategorization required to adequately capture the category components without adding needless complexity; two levels of sub-categorization was the maximum possible,

- category and constituent names used in the source documentation were kept intact when possible; changes were made only when it was necessary to provide more generic language (as in the case of plant conditions, where references to specific types of equipment were eliminated and equipment state was emphasized), and

- relevant HRA literature (especially Reason, 1990) was consulted when clarification was required. 


\subsection{Matrix Structure}

The result of the exercise described above was the five-dimensional quasi-hierarchical matrix shown as Figure 2-1. As depicted by the levels, three general types of questions must be answered for each UA being categorized:

- Describe the top-level conditions. What state was the system in at the time the UA occurred? Did the UA occur before or after the event initiator?

- What was the cognitive state of the operator as he4 took the UA? What were the cognitive demands and what was the mechanism for the resultant unsafe action? Both parts of the latter question must be answered to characterize the cognitive activity.

- What was the error-forcing context? Describe both the equipment/material conditions and the performance shaping factors.

In the interest of consistency with ATHEANA, the UA, rather than the overall event (which is the unit used for records in the database), was selected as the unit to be described by the matrix entries: ATHEANA's language regarding EFCs is specific to UAs. Likewise, different UAs likely involve different information processing stages and mechanisms. Finally, because events progress over time, it is possible that system status changes over the course of an event. Take as an example the case of an event involving latent equipment problems induced by maintenance personnel. Here, the first UA may have occurred days or weeks before the event was triggered, and may have occurred when the system was in an entirely different configuration (i.e., maintenance versus operating). (For an example of such an event, see the Augmented Inspection Team Report for Oconee Unit 3, 1991.) To describe an event, then, one would collate the information about each documented UA. Note that a particular

4 Throughout this report, "he" and "his" are used to refer to persons of either gender. 
System Status

Operating

Maintenance/Testing

Shut-down/Stand-by
Initiator Status

Pre-initiator

Post-initiator

Initiating Event

Level 2: Cognitive Activity Characterization

Unsafe Action Mechanism

Disabling a running system/

equipment

Starting a shut-down system

Equipment status

inappropriately changed

Wrong action sequence

Untimely action

Depletion of resources

Rate errors

Frequency errors

Quantity errors

Duration errors
Information Processing Stage

Monitoring/Detection

Situation Assessment

Response Planning

Response Implementation/

Execution

Level 3: Error-Forcing Context

Equipment/Material Condition

Performance Shaping Factors

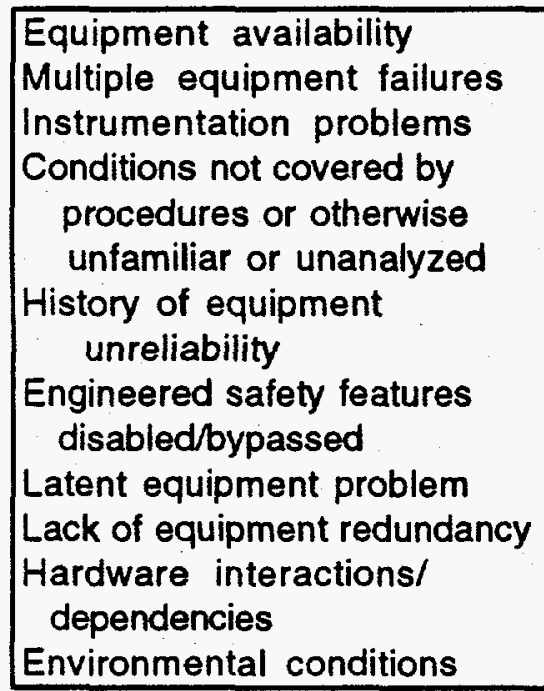

\begin{tabular}{|l|}
\hline Procedures/Policies \\
Training/Knowledge \\
Communication \\
Human-System Interface Design \\
Environmental Conditions \\
Organizational Factors \\
Supervision \\
Staffing \\
Experience \\
Informal Rules/Practices \\
Fatigue/Alertness \\
Shift Transition \\
Workload \\
Time Pressure \\
\hline
\end{tabular}


Figure 2-1. High-level view of the Action Characterization Matrix. 
UA may simultaneously trigger several cells in the equipment/material conditions and PSFs dimensions.

The matrix is described as "quasi-hierarchical" in the sense that the levels are intended to convey relationships between dimensions at the same level (i.e., that equipment/material conditions and PSFs combine to produce an error-forcing context) moreso than to define a hierarchy of the dimensions. Within particular dimensions, however, there may be intended hierarchies. Specifically, the system status requires sub-category specification.

\subsection{Explanation of Matrix Dimensions}

Details of the matrix dimensions and any sub-categories are given below. Note that a particular UA will be characterized in terms of a single subcategory under each of the following dimensions: system status, initiator status, unsafe action mechanism, and information processing stages. The UA may be represented by more than one entry from the equipment/material conditions and PSFs lists.

\subsubsection{System Status}

System status is the only dimension proposed for the ACM that was not directly addressed in ATHEANA. Such a dimension is, however, alluded to in the "activity" field in HERA, where activities include operations, maintenance, and testing.

System status has three categories (operating, maintenance/testing, and shut-down), each of which is further characterized by a number of subcategory descriptors. An operating system may exist in any one of six states: 
- start-up, which implies that power has been applied and the system is being made ready for normal operations; for example, in the aviation arena, at-power pre-flight checks and taxi activities would be considered start-up operating conditions;

- ramp-up, which is a transitional state between the application of power and full normal operations; to continue the aviation analogy, take-off would be considered a ramp-up operating condition,

- normal operation, which is also referred to as "nominal" in the ATHEANA documentation,

- off-normal operation, which is a transitional state indicating abnormal system conditions that are not of sufficient severity to trigger the use of emergency procedures

- emergency operation, in which emergency procedures supersede normal operational procedures, and

- ramp-down, a parallel to ramp-up which implies that the system is being transitioned from a fully operating configuration to an "at rest" state

Ramp-down leads to a shut-down or stand-by condition, either in a maintenance mode or with shut-down as the intended end state.

In general, normal operations are of least interest in ATHEANA. This attribution of importance to the various dimensions becomes significant in thinking about how to apply the ACM and is discussed in Section 3.1 below.

Maintenance/testing can occur in one of three configurations:

- operational, that is maintenance that occurs without removing power from the total system

- outage or shut-down, and

- stand-by, which implies that the system is placed in a less-than-full power safe and secure configuration 
Likewise, shut-down can be described as occurring in one of three ways:

- hot shut-down, which can be thought of as a stand-by condition,

- cold shut-down, which implies that power would need to be applied to the system before operations could proceed,

- decontamination and decommissioning, which may imply a change in license status in the NPP arena or a permanent removal from operations (scrapping) in other industries

\subsubsection{Initiator Status}

The UA can occur either prior to (pre-initiator) or after (post-initiator) the initiating event. Human failure events may themselves be initiators.

\subsubsection{Unsafe Action Mechanism}

Unsafe action mechanisms refer to the manner in which the human operator fails. Because of the difficulty in inferring intentionality, which is required for a specification of whether an action is an error of omission or commission, the unsafe action mechanisms focus on what the operator does (or fails to do), including:

- disabling an appropriately running piece of equipment or equipment system,

- starting an appropriately shut-down piece of equipment or equipment system,

- inappropriately changing equipment status, such as taking equipment out of automatic operation or disabling a system in armed/standby status,

- performing an inappropriate sequence of actions,

- taking action in an untimely manner, either too early or too late,

- taking actions that result in the inappropriate depletion of resources,

- performing rate errors by taking actions either too slowly or too quickly,

- performing frequency errors, by taking actions either too often or too infrequently,

- performing quantity errors, by taking too many or too few actions, and 
- performing duration errors, by taking actions for too long or too short a period

\subsubsection{Information Processing Stage}

The four information processing stages were drawn directly from the ATHEANA documentation; the stages are also explicitly called out in HERA. The order of the stages is somewhat arbitrary; they are described in different sequences at different places in the ATHEANA documentation.

Sub-categories were sometimes specified in the ATHEANA documentation (see, for example, response planning as described in the FOR Manual), and sometimes were implied. In some cases, the range of options (again, look at FOR Manual response planning descriptions) was curtailed in the interest of simplification. Sub-categories are described here as examples only; because of concerns regarding the reliability with which analysts could determine appropriate sub-categories, the ACM does not require specification at the sub-category level.

Failures in monitoring/detection are described in ATHEANA as resulting from one of four conditions:

- a response plan that does not specify the appropriate parameters to monitor,

- distractions,

- information that is ignored or discounted, and

- unavailability of information

We have elected to use these four conditions as the sub-categories by which to explain monitoring/detection, as they seem most descriptive. Note, however, that other taxonomic classifications (such as whether the failure was data-driven or knowledge-driven) are possible, and are also suggested in the ATHEANA documentation. Which construction is used may not be a matter of great import, however, as monitoring/detection failures are considered to be of lowest priority in ATHEANA.

Failures in situation assessment described in the ATHEANA documentation include problems in: 
- information transmission,

- information reception,

- interpretation, and

- monitoring, which is also described as a failure to update the situation model

In contrast to monitoring/detection, situation assessment is the most important of the information processing stages.

Response planning consists of six possible phases, each of which could be subject to error:

- goal identification,

- generation of response alternatives,

- evaluation and prioritization of alternatives,

- selection of an alternative,

- monitoring, and

- adaptation

Note that generation and evaluation of response alternatives may be eliminated as a possibility in cases where procedures specify the alternative(s) to select in various circumstances.

Failures in response implementation/execution can be further described as involving competition for resources (cognitive or manual) or communication failures between operators. The ATHEANA documentation suggests a third sub-category, namely failures due to slips and lapses.

\subsubsection{Equipment/Material Conditions}

The equipment/material conditions given as options in the $A C M$ were derived from descriptions provided in the ATHEANA documentation. In general, however, the language used in the ATHEANA descriptions of equipment/material conditions is very specific to the NPP environment. Thus, in developing the list of possible equipment/material conditions to include in the ACM, the "raw" ATHEANA descriptions were clustered into 
like groups and a generic name was placed on each category. It is these generic names that are used in the matrix.

Because the details of how particular equipment/material conditions (and also PSFs) contribute to the EFC are essentially unbounded, it did not seem feasible to try to refine their descriptions through the use of subcategories. Thus, both the equipment/material conditions and PSFs dimensions occur only at a single level having a number of alternatives. For equipment/material conditions, these include:

- Equipment availability -- usually it is failed or unavailable equipment that is of concern, however, there are instances where the fact that a piece of equipment was available serves to set up the event,

- Multiple failures,

- Instrumentation problems (non-failure), which includes misleading indications, lack of precision of indicators (i.e., requiring the operator to interpolate), layout not conducive to the activity being performed, and lack of timeliness of indications,

- Conditions not covered by procedures or otherwise unfamiliar or unanalyzed, which may also occur as a result of such things as multiple failures, dynamic events, or the need to manually control automatic systems,

- History of equipment unreliability, including a history of false alarms or spurious indications,

- Latent or undiscovered equipment problems; these are usually humaninduced but occur at a time prior to the event and include things such as inappropriate or incorrect maintenance actions (such as the incorrect installation of a flange in the Oconee Unit 3 event),

- Lack of equipment redundancy,

- Hardware interactions/dependencies, and

- Environmental conditions (such as extreme cold) that affect equipment

Note that a particular UA may involve several "contingent" equipment/material conditions. That is, any equipment/material condition that played a role in the UA should be noted; other equipment/material conditions that may have been present but that did not contribute to the UA should be ignored. This same philosophy applies in recording PSFs. 


\subsubsection{Performance Shaping Factors}

The starting point for the list of PSFs were those used in the Human Performance Investigation Process (HPIP) and documented in NUREG/CR5455 (Paradies, et. al., 1993). These include:

- Procedures/policies,

- Training, which is intended to include the availability of relevant knowledge even if such knowledge was not acquired through formal means and is called out as such in the matrix,

- Communication,

- Supervision,

- Staffing,

- Human-system interface design, including equipment layout and workplace ergonomics (which is a departure from the view of some authors, including the ATHEANA team, who include ergonomics under environmental conditions),

- Organizational factors, including management decisions regarding production goals,

- Stress, and

- Environmental conditions, including light, noise, etc., that affect human operators

In looking at the ATHEANA documentation, however, it became obvious that the events used as examples had been described in more detail than could be captured using this list alone. In particular, a number of different forms of "stress" were described including:

- Fatigue/alertness,

- Shift transition,

- Workload, and

- Time pressure

Thus, the more generic term "stress" was removed from the list of PSFs and the four more detailed items were substituted. 
In addition, two other items which were commonly discussed as contributors to EFCs in the ATHEANA documentation were added:

- Experience, which is distinguished from the training/knowledge factor by virtue of the operator having actually performed the activity of interest previously, and

- Informal rules and practices

The current database structure includes only the fields corresponding to the HPIP PSFs, so will need to be expanded to incorporate the more detailed list. Events already analyzed using the more restrictive set of PSFs will need to be reviewed to see whether any items from the expanded list are applicable. 


\section{References}

Augmented Inspection Team Report, Oconee Unit 3, March 8, 1991, Loss of Residual Heat Removal. (April 10, 1991). Report No. 50-287/91-008, U. S. Nuclear Regulatory Commission: Washington, DC.

Bley, D., Cooper, S., Forester, J., Kolaczkowski, A., and Wreathall, J. (June, 1997). A Technique for Human Error Analysis (ATHEANA) Implementation Guidelines. Draft NUREG/CR.

Cooper, S. E., Luckas, W. J. Jr, and Wreathall, J. (December 21,1995). Human-System Event Classification Scheme (HSECS) Database Description. Brookhaven National Laboratory Technical Report L-2415/95-1.

Paradies, M., Unger, L., Haas, P. M., and Terranova, M. (October, 1993). Development of the NRC's Human Performance Investigation Process (HPIP). NUREG/CR-5455. System Improvements, Inc: Aiken, SC.

Reason, J. (1990). Human Error. Cambridge University Press.

Taylor, J. H., O'Hara, J., Luckas, W. J., Parry, G. W., Cooper, S. E., Roth, E., Bley, D. C., and Wreathall, J. (March, 1997). Frame-of-Reference Manual for ATHEANA: A Technique for Human Error Analysis. Draft NUREG/CR. 


\section{Appendix A: Glossary5}

\begin{tabular}{|l|l|}
\hline $\begin{array}{l}\text { Error-forcing } \\
\text { context }\end{array}$ & $\begin{array}{l}\text { The situation that arises when particular } \\
\text { combinations of performance shaping factors and } \\
\text { equipment/material conditions create an } \\
\text { environment in which unsafe actions are more likely } \\
\text { to occur. }\end{array}$ \\
\hline $\begin{array}{l}\text { Human failure } \\
\text { event }\end{array}$ & $\begin{array}{l}\text { A basic event that is modeled in the logic models of } \\
\text { a PRA (event and fault trees) and that represents a } \\
\text { failure of a function, system, or component that is } \\
\text { the result of one or more unsafe actions. A human } \\
\text { failure event reflects the PRA systems modeling } \\
\text { perspective. }\end{array}$ \\
\hline $\begin{array}{l}\text { Performance } \\
\text { shaping factors }\end{array}$ & $\begin{array}{l}\text { A set of influences on the performance of an } \\
\text { operating crew resulting from the human-related } \\
\text { characteristics of the plant, crew, and the individual } \\
\text { operators. The characteristics include procedures, } \\
\text { training, and human factors aspects of the displays } \\
\text { and control facilities of the plant. }\end{array}$ \\
\hline $\begin{array}{l}\text { Equipment/ } \\
\text { material } \\
\text { conditions }\end{array}$ & $\begin{array}{l}\text { The plant state defined by combinations of its } \\
\text { physical properties and equipment conditions, } \\
\text { including the measurement of parameters. }\end{array}$ \\
\hline Unsafe action & $\begin{array}{l}\text { Actions inappropriately taken, or not taken when } \\
\text { needed, by plant personnel that results in a degraded } \\
\text { plant safety condition. }\end{array}$ \\
\hline
\end{tabular}

5 Many glossary entries were taken from the ATHEANA FOR Manual or IG. 